UDC: 378.147

DOI: 10.26697/ijes.2019.2.15

\section{Methodological Provider for Students of Foreigners in the Modern Educational Space}

\author{
Nosivets D. S. ${ }^{1}$ \\ ${ }^{1}$ SI "Dnipropetrovsk Medical Academy of the Ministry \\ of Health of Ukraine”, Ukraine
}

\begin{abstract}
Background:

Today, an increasing number of foreigners from different countries come to Ukraine for study at higher educational institutions, including our medical academy. Therefore, a very topical issue is the use of new innovative pedagogical technologies in the educational process in a system that corresponds to the world level, in particular, when studying such disciplines as "pharmacology" and "clinical pharmacology". According to contemporary authors, the active search for new forms and methods of higher medical education is very important, which would help to maximize the preparation of foreign students to the level of specialists of international standards, which requires constant search and use of innovative approaches to the educational process.

The aim of the study is to highlight the experience of introducing innovative teaching methods for foreign students, which are used in teaching subjects "pharmacology" and "clinical pharmacology".
\end{abstract}

\section{Results:}

To improve the quality of teaching, the services of foreign students are equipped with experimental laboratories, computer class, which positively influenced the increasing interest of students in research and experimental work. This event is aimed at improving the intellectual and professional level of future physicians. The highest level of research work is the preparation of individual work by students in the state and English languages and their presentation at scientific and practical conferences for young scientists and students. To date, a number of foreign students have become masters or graduate students of our academy and have continued their research.

At our department special attention is paid to attracting students to research work. For the development of the creative abilities of foreign students according to the number of hours for non-auditing work, it is recommended to prepare reports on selected topics at the sessions of the student scientific society, to prepare stands, presentations, catalogs of medicines, with special attention being given to the international names of medicines.

In order to develop the creative abilities of foreign students, according to the number of hours for nonauditing work in accordance with the curriculum, it is recommended to prepare reports on selected topics at classes, meetings of student scientific societies, preparation of stands, presentations, catalogs of medicinal preparations, where particular attention is paid to international names of medicines.
An important place is the development of teaching aids for practical classes, which include theoretical questions for classes, test questions, a list of drugs by subject and tasks for non-auditing work. Foreign students are able to work with these guides by filling out a special table for compulsory medical products, prescribing recipes, solving situational tasks, and completing tests for STEP-1. Thus, the conditions for the ongoing control of the tasks performed in practical employment and the analysis of errors are formed, and in the educational process feedback will be traced, which is very important for the foreign students. In practical classes not only is the control, but also the discussion of topics, the students are given answers to the specific questions of the teacher, the conduct of listening to abstracts, etc., which allows foreign students to openly demonstrate acquired knowledge, as well as practical skills and abilities, and see the component of their grades for classes. Special attention on practical classes is given to students solving situational tasks, which includes elements of the professional growth of future doctors. For qualitative conducting of practical classes video films and methodical developments are used.

Consequently, the placement of grades for classes is not just a student's control. Methods of training should increase the student's motivation to master the material from discipline. Students have the opportunity to departmen's website to enjoy educational and methodical cases, which contains information on the structure, purpose and content of the discipline, principles of evaluation, calendar and thematic lesson plans, schedules of consultation, intermediate and final control, and information needed to preparation for a particular training session (information on the relevance of the subject, its duration, educational purpose, the question for self-control, the list of recommended literature).

\section{Conclusions:}

Thus, the proposed methods and measures to improve the quality of foreign students in today's educational environment can be considered innovative because they contribute not only to optimize the learning process, but also allow to train professionals whose main focus in training is motivation, which allows to adapt future doctors to the requirements of international systems and standarts and to be specialists in any section of medicine where the basis of effective treatment of patients is a good basic knowledge of the subjects of "pharmacology" and "clinical pharmacology".

\section{Information about the author:}

Nosivets Dmitriy Sergeevich - Doctor of Philosophy in Medicine, Assistant Professor, Department of Pharmacology and Clinical Pharmacology, SI "Dnipropetrovsk Medical Academy of the Ministry of Health of Ukraine", Dnipro, Ukraine.

Research interests: clinical pharmacology, orthopedics, osteoarthritis; http://orcid.org/0000-0001-9954-6027.

\section{Corresponding Author:}

Nosivets Dmitriy Sergeevich

Corresponding Author's Email:

dsnosivets@ukr.net 